\title{
A randomized controlled trial on the effect of remote ischemic preconditioning on ERK1, ERK2, STAT3 and STAT 5 in patients with and without diabetes mellitus undergoing CABG surgery
}

\section{Daniel Brevoord ( $\boldsymbol{\sim}$ d.brevoord@gmail.com)}

Amsterdam Universitair Medische Centra https://orcid.org/0000-0002-3701-2924

Kirsten F. Smit

Amsterdam Universitair Medische Centra

Yimming Wang

Amsterdam Universitair Medische Centra

Markus W. Hollmann

Amsterdam Universitair Medische Centra

Raphaella P. Kerindongo

Amsterdam Universitair Medische Centra

Nina C. Weber

Amsterdam Universitair Medische Centra

Benedikt Preckel

Amsterdam Universitair Medische Centra

Research article

Keywords:

Posted Date: May 7th, 2019

DOI: https://doi.org/10.21203/rs.2.9489/v1

License: (c) (1) This work is licensed under a Creative Commons Attribution 4.0 International License. Read Full License 


\section{Abstract}

Background Remote ischemic preconditioning (RIPC) is less effective in patients with diabetes, and the molecular mechanisms behind this lack of protection are not fully understood. In this study we investigated the effects of remote ischemic preconditioning on the intracellular signal cascade (known as the RISK pathway), e.g. ERK1/2, STAT3 and STAT5 in patients with and without diabetes undergoing coronary artery bypass graft (CABG) surgery. Methods Twenty-six patients with and 24 patients without diabetes mellitus undergoing CABG surgery under a total-intravenous, propofol based anesthetics regime, were randomized to either remote ischemic preconditioning induced by $3 \times 5$ minutes of forearm ischemia or untreated controls. In each patient, two atrial tissue samples were collected: the first before, and the second after preconditioning, but before initiation of cardiopulmonary bypass. Tissue samples were homogenized and the ratio of total-to-phosphorylated ERK1 and 2, STAT 3 and STAT 5 were determined by Western Blotting. Myocardial injury after CABG was assessed by analyzing postoperative troponin release. Results In the patients without diabetes, no effect of RIPC on any of the molecular markers was observed. In addition, we found no reduction in postoperative peak troponin release after RIPC. In patients with diabetes, ERK1 and ERK2 phosphorylation was increased in the control group, while in the RIPC treated patients only ERK2 was significantly increased. STAT3 phosphorylation was increased in both, the control and RIPC group, while there was no effect on STAT5 phosphorylation. Again, there was no effect on postoperative troponin release. Discussion We found no effect of RIPC on ERK 1, ERK2, STAT 3 or STAT 5 in either patients with or without diabetes. Additionally, there was no reduction in troponin T release by RIPC. The major limitation of our trial is the small sample size. Trial registration The trial was prospectively registered in the Dutch trial register as NTR1931.

\section{Background}

Remote ischemic preconditioning (RIPC) has become a promising method of providing protection against ischemia reperfusion injury, most notably in cardiac surgery. $(1,2)$ Even after recent large trials showed negative results, $(3,4)$ RIPC remains an intriguing concept.

Preconditioning is less effective in patients with diabetes mellitus, $(5,6)$ while simultaneously these patients have an increased risk for adverse cardiovascular events.(7-9) Not only is the risk of sustaining an acute myocardial infarction or requiring coronary revascularization increased for patients with diabetes; they also suffer from increased myocardial injury and poorer outcomes when these events occur. $(10,11)$

How diabetes interferes with remote conditioning is not fully understood. RIPC activates intracellular prosurvival kinases, commonly referred to as RISK and SAFE pathways. $(12,13)$ Key components include extracellular signal-regulated kinase 1/2 (ERK-1/2), protein kinase B (Akt)(14), protein kinase C(PKC),(15) signal transducer and activation of transcription 3 (STAT3)(16) and/or signal transducer and activation of transcription 5 (STAT5) $(17,18)$. The common target for these pathways seems to be the mitochondria, where opening of mitochondrial potassium channels $\left(\mathrm{K}_{\mathrm{ATP}}\right)$ helps to stabilize the membrane, and helps to 
prevent opening of the mitochondrial permeability transition pore (MPTP), thereby preventing apoptosis. (19) Animal studies indicated that most of the important intracellular kinases involved in ischemic preconditioning are downregulated in diabetic subjects.(20) However, clinical data on RIPC in patients with diabetes is scarce since most clinical trials excluded these patients. Nevertheless, subgroup analysis of larger trials that did include patients with diabetes suggest that cardioprotection by remote ischemic preconditioning is abolished by diabetes. $(14,21)$

We present a randomized controlled trial investigating the effects of RIPC on known mediators of cardioprotection in diabetic and non-diabetic patients. We aimed to confirm that remote conditioning activates STAT 3 or STAT 5 and we hypothesize that the activation of these kinases is diminished in diabetic patients.

\section{Methods}

\section{Subjects and setting}

\section{This study was a randomized controlled single-center trial, performed at an academic center. The study was approved by the local medical ethics committee and conducted in accordance to the principles of the Declaration of Helsinki. The trial was registered in the Dutch trial register as NTR1931. All participants provided written informed consent. The study adhered to the CONSORT statement on reporting on clinical trials.(22)}

We recruited patients scheduled for elective coronary artery bypass grafting (CABG) surgery, with or without concurrent aortic valve repair. Exclusion criteria were an age $<18$ years, severe organ dysfunction, including left ventricular ejection fraction $<30 \%$, severe chronic obstructive pulmonary disorder or SpO2 $<90 \%$ at room air, renal clearance $<30 \mathrm{ml} / \mathrm{min}$, liver failure, or the use of the antidiabetic drug glibenclamide which is known to block protection by preconditioning. $(21,23)$

\section{Study procedures}

Patients were randomized 1:1 to either a control or intervention group, using a web-based application (ALEA; NKI, Amsterdam, The Netherlands) with a random block method and stratified for diabetes.

Patients were blinded to treatment allocation, as was the investigator performing the laboratory analyses. The anesthesiologist was not blinded, and although the surgeons were unaware of group allocation, we didn't take special precautions to prevent them from becoming aware whether a cuff was inflated on the patients arm or not. 
Standard monitoring was used, including an arterial line, central venous catheter and trans-esophageal echocardiography. Anesthesia was induced and maintained using a total intravenous anesthesia regimen consisting of midazolam, propofol, sufentanil and rocuronium.

In all patients a researcher placed a pneumatic tourniquet on the upper arm on the side without arterial line or intravenous cannula. In the control group, no further intervention was done and tissue samples were collected as described later. In the intervention group, after obtaining the first tissue sample, the tourniquet was inflated to $200 \mathrm{mmHg}$ during 3 cycles of 5 minutes, with 5 minutes deflating the cuff between the cycles.

Two samples of right atrial tissue were taken during the procedure. After opening of the sternum but before harvesting of the left internal mammary artery, the surgeon took the first sample at the site where the venous cannula for bypass would later be inserted and closed the resection point with a suture. Later, when the right atrium was cannulated, the second biopsy was taken. Tissue samples were immediately frozen in liquid nitrogen before storage at $-80^{\circ} \mathrm{C}$.

\section{Outcome}

The study was designed to compare the effects of RIPC on biochemical markers ERK 1 and 2, STAT3 and STAT5 between patients with and without diabetes. We analyzed the data as if there were two separate studies, one with only patients without diabetes, and the other one with only patients with diabetes. Additionally, we pooled the data of patients with and without diabetes.

\section{Primary outcome parameter}

Initially (see Dutch trial register NTR1931), the study planned to analyze differences in phosphorylation of the signaling enzymes ERK1, ERK2, HSP27 and PKC. $(24,25)$ However, during the inclusion period, new, most likely more relevant markers of RIPC in humans had been published.(17) We therefore adjusted the biochemical analyses and investigated the effect of RIPC on ERK 1 and 2, STAT3 and STAT5.

\section{Secondary outcome parameters}

Myocardial injury was estimated by comparing the peak postoperative troponin values. We used the data collected for postoperative monitoring of troponin on the ICU, and samples were generally taken at arrival on the ICU, 4 hours later and at 6.00 AM the next day. In patients with significantly increased troponin values, samples were drawn more frequently to monitor possible myocardial injury.

We assessed clinical outcome by examining the charts and discharge letter from the ICU.

\section{Laboratory analyses}


Tissue samples were homogenized and separated into cytosolic, membrane and particulate fraction before analyzing. The samples were crushed and dissolved in a lysis buffer consisting of Sigma 7-9, EGTA, NaF, Na3VO4 with the freshly added proteases aprotinin, lepetin and pepsatin, and DTT and okadaic acid. They were kept on ice until they were centrifuged at $530 \mathrm{G}$ at $4^{\circ} \mathrm{C}$ for 10 minutes. The supernatant, containing the cytosolic fraction, was centrifuged again at $13.000 \mathrm{G}$ at $4^{\circ} \mathrm{C}$ for 15 minutes to clean up reaming debris. The pellet from the first step was dissolved in lysis buffer with $1 \%$ Triton and incubated for 60 minutes on ice. Then, this solution was centrifuged at $13.000 \mathrm{G}$ at $4^{\circ} \mathrm{C}$ for 15 minutes. The supernatant containing the membrane fraction was transferred and the pellet containing the particulate fraction was dissolved in lyses buffer.

Western Blotting was performed as described previously.(26) Protein content was quantified using the Lowry method,(27) and the proteins were separated by electrophoresis using Criterion ${ }^{\mathrm{TM}} \mathrm{XT}$ precast gels (Biorad, Hercules, CA) and transferred to a polyvinyliden fluorid membrane (Immobilin-FL, Licor, Bad Homburg, Germany). These membranes were incubated with the primary antibodies: pERK 1:1000, ERK 1:5000, pSTAT3 1:500, STAT3 1:000, pSTAT5 1:500 and STAT5 1:1000. They were then washed with phosphate buffered saline containing tween, incubated with a suitable secondary antibody and washed again. Thereafter, the membranes were scanned using the Odyssey Infrared Imaging System (Licor) and the signal intensity quantified using Odyssey Imaging Studio Software (Licor).

\section{Sample size calculation}

Sample size was based on previous work on the cardioprotective effect and molecular changes by sevoflurane.(28) We therefore assumed a sample size of 12 patients would be sufficient to detect a difference in patients without diabetes. We expected the molecular changes in patients with diabetic to be less profound and therefore increased the sample size in these patients to 16 subjects per group. This led to a total sample size of 56 patients.

StatisticsSPSS v24 (IBM, Armonk, New York, USA) was used for statistical analysis. Continuous data are presented as mean with standard deviation when normally distributed, or otherwise as median and interquartile range. Categorical data are presented as numbers with proportions. Student's $t$-test was used for normally distributed data, or skewed data after log transformation when appropriate, and the MannWhitney $\mathrm{U}$ test or Wilcoxon signed rank test for not normally distributed data. Statistical significance was defined as $p \leq 0.05$. Figures were created using GraphPad Prism v7.

\section{Results}

\section{Baseline characteristics and study procedures}

From august 2009 until October 2011, 50 patients (24 patients without diabetes and 26 with diabetes) were included. Due to concurrent trials the inclusion of the last patients proved to be difficult. We felt that storing the samples longer would not be beneficial, and decided to terminate the trial. 


\section{Patients without diabetes}

Of 24 patients without diabetes, 13 were randomized to the control group and 11 to the intervention group. Groups were well matched for known risk factors and medication usage (Table 1). One patient in the intervention group accidentally received sevoflurane during the procedure; otherwise the study intervention was executed according to protocol. In the control group, 1 patient developed postoperative atrial fibrillation, 1 patient underwent a percutaneous coronary intervention and 1 patient had a rethoracotomy for excessive bleeding. In the intervention group, 2 patients suffered from postoperative atrial fibrillation.

\section{Patients with diabetes}

Of 26 patients with diabetes, 13 were randomized to the control group and 13 to the intervention group. In the control group there were more smokers (10 vs 3 ), but groups were well matched otherwise. Cardiac tissue samples were not collected in 1 patient in the intervention group. In the control group, 1 patient had postoperative atrial fibrillation; in the intervention group, 3 patients suffered from atrial fibrillation, 1 patient had a delirium and 1 patient had a compartment syndrome postoperatively.

\section{Western Blotting}

Part of the tissue samples was processed during the trial, and the rest at the conclusion of the trail. However, due to the significant time delay we felt that the stored samples would probably produce different results compared to freshly processed samples, especially regarding the phosphorylated fraction of proteins. Therefore, we finally only analyzed the recently processed samples. Additionally, the protein content of 2 samples of 2 different patients in the non-diabetic intervention group was too low for Western Blotting, leaving a sample size of 4 non-diabetic patients treated with RIPC and 6 subjects in all other groups. Patients without diabetes

We observed an increase in the ratio of phosphorylated versus total ERK1 in both the control group as the intervention group, but this was not statistically significant at $p=0.06$ and $p=0.23$. No difference in $p / t$ ratio of ERK2 was seen in either group (figure1).

In the control group there was no difference in $\mathrm{p} / \mathrm{t}$ ratio of STAT3. In the RIPC group we observed an increase in the $p / t$ ratio after preconditioning, but this did not reach statistical significance $(p=0.14)$.

There was no difference in the $\mathrm{p} / \mathrm{t}$ ratio of STAT5 in either of the groups.

\section{Patients with diabetes}

We observed a significant increase in the $p / t$ ratio of ERK1 in the control group $(p<0.01)$, but not in the RIPC group ( $p=0.07)$. For ERK2, we found a significant increase in both groups (figure 2 ). 
For STAT3, the $p / t$ ratio increased significantly in both the control group, and the RIPC group ( $p=0.03$ for both groups).

No difference on STAT5 p/t ratio was seen in either group.

\section{All patients}

There was an increase in the p/t ratio of ERK1 in both the control and the intervention group (figure 3 ).

For ERK2, only the control group showed a significant increase in $\mathrm{p} / \mathrm{t}$ ratio.

We observed in both groups a significant increase in the $\mathrm{p} / \mathrm{t}$ ratio of STAT3.

There was no effect on the $\mathrm{p} / \mathrm{t} /$ ratio of STAT5.

\section{Myocardial injury}

In the patients without diabetes there was no difference in peak troponin value between groups $(0.85 \pm 0.8$ in the control group versus $1.1 \pm 1.2$ in the intervention group, $p=0.91$ ) (figure 4). Neither was there a difference in peak troponin value between groups in the patients with diabetes $(0.91 \pm 1.5$ in the control group vs $0.6 \pm 0.39$ in the intervention group, $p=0.34$ ). Also, when combining the data on patients with or without diabetes, we found no difference between patients subjected to remote conditioning or control treatment $(0.88 \pm 1.2$ in control patients vs $0.83 \pm 0.89$ in conditioned patients, $p=0.31)$ (figure 5 ).

\section{Discussion}

This is to our knowledge the first study specifically looking at the molecular effects of RIPC in diabetic patients undergoing cardiac surgery. In this randomized controlled trial we observed no effect of RIPC on ERK1, ERK2, STAT3 or STAT5. We did find an increase in phosphorylation of ERK1, ERK2 and STAT3 over time in patients with diabetes, with no differences between control and intervention groups. And in the patients without diabetes we observed a non-significant increase in STAT3 phosphorylation by RIPC.

We did not observe a reduction in troponin release with RIPC in either patient population. Although this study was not powered to detect a difference in troponin release, similar sized trials did find a reduction in biomarker release.(1) Also, using peak troponin levels derived from the clinically collected samples might be less sensitive than sequential sampling and calculating the area under the curve. However, in STEMI patients treated with primary $\mathrm{PCl}$, peak values of troponin were similarly predictive of infarct size as areaunder-the-curve of troponin release was.(29)

The main limitation on these findings is that the number of usable cardiac samples was smaller than anticipated at the design of the trial, thereby reducing sample size and power. This is especially true for the non-diabetic patients. This unfortunately makes it difficult to draw strong conclusions from our data. 
Another possible limitation of this study is the choice of anesthetics. A great number of factors can affect preconditioning-like cardioprotection during cardiac surgery, including drugs taken by the patient preoperatively as well as those administered during surgery; Beta-blockers, statins, antidiabetic drugs and opioids are a just a few, although the effects are not always well established. $(23,30-32)$ Of special interest are the anesthetic drugs that are being used. Volatile anesthetics are known to induce preconditioning and it would be expected that this could interfere with remote ischemic preconditioning, for example, by making it more difficult to demonstrate an additional benefit. $(28,33-35)$ Indeed, in a meta-analysis of randomized trials remote ischemic preconditioning seemed less effective in patients undergoing cardiac surgery using a volatile anesthetics.(32) This reasoning led us to use a total intravenous anesthesia with propofol. Contrary, other studies suggest that it is a propofol based anesthesia that inhibits remote ischemic preconditioning and reduces its protective effects. $(36,37)$ In a subset of patients from a larger randomized trial Kottenenberg et all found that remote ischemic preconditioning could reduce the area under the curve of troponin I release by $50 \%$ in isoflurane anesthetized patients, but with only $30 \%$ in patients under propofol anesthesia, which was lower than the expected $40 \%$ used in their power calculation and therefore not significant.(36) Then again, another recent randomized trial strictly avoiding propofol did not see a reduction in troponin $T$ release by remote ischemic preconditioning.(38) Overall, it is likely that the choice of anesthetics could have influenced the results of our trial, although the exact way is less clear.

This study contrasts with previous studies. Heusch et al. investigated multiple molecular targets and found specifically STAT5 activated by RIPC,(17) while Gedik et al. showed an increased activation of STAT3 by RIPC in non-diabetic patients.(16) In children with congenital heart disease, both STAT3 and STAT 5 were activated by RIPC.(39) On the other hand, Kottenberg et al. found no effect of RIPC on either STAT3 or STAT5, which might have been due to the effects of propofol anesthesia.(40) However, in these studies no patients with diabetes were included.

Indeed, there are very few studies investigating RIPC in diabetic patients. In a small subgroup from a larger trial, Kottenberg et al. reported no effect of RIPC on troponin I release after CABG surgery in patients with diabetes treated with sulfonylurea derivatives.(21) In a trial following elective PCl in diabetic patients, RIPC failed to reduce myocardial injury.(41)

The signal cascade involved in conditioning seems less suited for preconditioning in diabetic patients. (20) In type 2 diabetics undergoing CABG surgery, atrial tissue contains increased levels of phosphatase and tensin homolog, which inhibits preconditioning, and reduced levels of phosphorylated AKT, Bcl and endothelial nitric oxide synthetase.(42) The mitochondria of patients with diabetes appear more susceptible to ischemic injury, due to an increased sensitivity to intracellular $\mathrm{Ca}^{2+}$ and thereby increased tendency for the MPTP to open.(43)

\section{Conclusions}


In conclusion, in this trial specifically designed to examine remote ischemic preconditioning in patients with diabetes and those without, we found no effect of remote ischemic preconditioning on ERK1, ERK2, STAT3 or STAT5 or troponin release.

\section{Abbreviations}

RIPC: remote ischemic preconditioning

ERK-1/2: extracellular signal-regulated kinase $1 / 2$

Akt: protein kinase $B$

PKC: protein kinase $\mathrm{C}$

STAT3: signal transducer and activation of transcription 3

STAT5: signal transducer and activation of transcription 5

$\mathrm{K}_{\text {ATP }}$ : potassium channel

mPTP: mitochondrial permeability transition pore

CABG: coronary artery bypass grafting surgery

\section{Declarations}

Ethics approval and consent to participate

The study was approved by the Medical Ethics Committee of the Academic Medical Centre, Amsterdam, Netherlands, its reference number is MEC 09/008. All study participants provided written informed consent prior to inclusion in the study.

Consent for publication

Not applicable

Availability of data and materials

The datasets used and analyzed are available from the corresponding author on reasonable request.

Competing interests

None of the authors have competing interests to declare.

Funding 
The study was funded by the department of Anesthesiology, Academic Medical Centre, University of Amsterdam. The funder has no role in the design of the study, collection or analysis of data or writing the manuscript.

Author contributions

$\mathrm{KS}, \mathrm{MH}, \mathrm{NW}$ and BP designed the study. DB, KS and BP included the patients, performed the study protocol and collected clinical data. DB, KS, YW and RK processed and analyzed the myocardial tissue samples. DB, KS, NW and BP analyzed and interpreted the data. All authors contributed to writing the manuscript and approve its final version.

Acknowledgements

Not applicable

\section{References}

1. Hausenloy DJ, Mwamure PK, Venugopal V, Harris J, Barnard M, Grundy E, et al. Effect of remote ischaemic preconditioning on myocardial injury in patients undergoing coronary artery bypass graft surgery: a randomised controlled trial. Lancet. 2007;370(9587):575-9.

2. Thielmann M, Kottenberg E, Boengler K, Raffelsieper C, Neuhaeuser M, Peters J, et al. Remote ischemic preconditioning reduces myocardial injury after coronary artery bypass surgery with crystalloid cardioplegic arrest. Basic research in cardiology. 2010;105(5):657-64.

3. Hausenloy DJ, Candilio L, Evans R, Ariti C, Jenkins DP, Kolvekar S, et al. Remote Ischemic Preconditioning and Outcomes of Cardiac Surgery. The New England journal of medicine. 2015;373(15):1408-17.

4. Meybohm P, Bein B, Brosteanu O, Cremer J, Gruenewald M, Stoppe C, et al. A Multicenter Trial of Remote Ischemic Preconditioning for Heart Surgery. The New England journal of medicine. 2015;373(15):1397-407.

5. Hassouna A, Loubani M, Matata BM, Fowler A, Standen NB, Galiñanes M. Mitochondrial dysfunction as the cause of the failure to precondition the diabetic human myocardium. Cardiovascular research. 2006;69(2):450-8.

6. Miki T, Itoh T, Sunaga D, Miura T. Effects of diabetes on myocardial infarct size and cardioprotection by preconditioning and postconditioning. Cardiovascular diabetology. 2012;11(1):67.

7. Singh GM, Danaei G, Farzadfar F, Stevens GA, Woodward M, Wormser D, et al. The age-specific quantitative effects of metabolic risk factors on cardiovascular diseases and diabetes: a pooled analysis. PloS one. 2013;8(7):e65174. 
8. Kannel WB, McGee D. Diabetes and glucose tolerance as risk factors for cardiovascular disease: the Framingham study. Diabetes care. 1979;2(2):120-6.

9. Collaboration ERF. Diabetes mellitus, fasting blood glucose concentration, and risk of vascular disease: a collaborative meta-analysis of 102 prospective studies. The Lancet. 2010;375(9733):2215-22.

10. Marso SP, Miller T, Rutherford BD, Gibbons RJ, Qureshi M, Kalynych A, et al. Comparison of myocardial reperfusion in patients undergoing percutaneous coronary intervention in ST-segment elevation acute myocardial infarction with versus without diabetes mellitus (from the EMERALD Trial). The American journal of cardiology. 2007;100(2):206-10.

11. Alegria JR, Miller TD, Gibbons RJ, Yi Q-L, Yusuf S. Infarct size, ejection fraction, and mortality in diabetic patients with acute myocardial infarction treated with thrombolytic therapy. American heart journal. 2007;154(4):743-50.

12. Hausenloy DJ, Yellon DM. New directions for protecting the heart against ischaemia-reperfusion injury: targeting the Reperfusion Injury Salvage Kinase (RISK)-pathway. Cardiovascular research. 2004;61(3):448-60.

13. Lecour S. Multiple protective pathways against reperfusion injury: a SAFE path without Aktion? Journal of molecular and cellular cardiology. 2009;46(5):607-9.

14. Slagsvold KH, Moreira JB, Rognmo O, Hoydal M, Bye A, Wisloff U, et al. Remote ischemic preconditioning preserves mitochondrial function and activates pro-survival protein kinase Akt in the left ventricle during cardiac surgery: a randomized trial. Int J Cardiol. 2014;177(2):409-17.

15. Speechly-Dick M, Grover G, Yellon D. Does ischemic preconditioning in the human involve protein kinase $\mathrm{C}$ and the ATP-dependent $\mathrm{K}+$ channel?: studies of contractile function after simulated ischemia in an atrial in vitro model. Circulation Research. 1995;77(5):1030-5.

16. Gedik N, Thielmann M, Kottenberg E, Peters J, Jakob H, Heusch G, et al. No Evidence for Activated Autophagy in Left Ventricular Myocardium at Early Reperfusion with Protection by Remote Ischemic Preconditioing in Patients Undergoing Coronary Artery Bypass Grafting. PloS one. 2014;9(5).

17. Heusch G, Musiolik J, Kottenberg E, Peters J, Jakob H, Thielmann M. STAT5 activation and cardioprotection by remote ischemic preconditioning in humans: short communication. Circ Res. 2012;110(1):111-5.

18. Kleinbongard P, Skyschally A, Gent S, Pesch M, Heusch G. STAT3 as a common signal of ischemic conditioning: a lesson on "rigor and reproducibility" in preclinical studies on cardioprotection. Basic research in cardiology. 2018;113(1):3.

19. Dos Santos P, Kowaltowski AJ, Laclau MN, Seetharaman S, Paucek P, Boudina S, et al. Mechanisms by which opening the mitochondrial ATP-sensitive $\mathrm{K}+$ channel protects the ischemic heart. American 
Journal of Physiology-Heart and Circulatory Physiology. 2002;283(1):H284-H95.

20. Lejay A, Fang F, John R, Van JA, Barr M, Thaveau F, et al. Ischemia reperfusion injury, ischemic conditioning and diabetes mellitus. Journal of molecular and cellular cardiology. 2016;91:11-22.

21. Kottenberg E, Thielmann M, Kleinbongard P, Frey UH, Heine T, Jakob H, et al. Myocardial protection by remote ischaemic pre-conditioning is abolished in sulphonylurea-treated diabetics undergoing coronary revascularisation. Acta Anaesthesiol Scand. 2014;58(4):453-62.

22. Schulz KF, Altman DG, Moher D. CONSORT 2010 statement: updated guidelines for reporting parallel group randomised trials. BMC medicine. 2010;8(1):18.

23. Ye Y, Perez-Polo JR, Aguilar D, Birnbaum Y. The potential effects of anti-diabetic medications on myocardial ischemia-reperfusion injury. Basic research in cardiology. 2011;106(6):925-52.

24. Weber NC, Toma O, Wolter JI, Obal D, Müllenheim J, Preckel B, et al. The noble gas xenon induces pharmacological preconditioning in the rat heart in vivo via induction of PKC-epsilon and p38 MAPK. British journal of pharmacology. 2005;144(1):123-32.

25. Weber NC, Toma O, Wolter JI, Wirthle NM, Schlack W, Preckel B. Mechanisms of xenon-and isofluraneinduced preconditioning-a potential link to the cytoskeleton via the MAPKAPK-2/HSP27 pathway. British journal of pharmacology. 2005;146(3):445-55.

26. Smit KF, Konkel M, Kerindongo R, Landau MA, Zuurbier CJ, Hollmann MW, et al. Helium alters the cytoskeleton and decreases permeability in endothelial cells cultured in vitro through a pathway involving Caveolin-1. Scientific reports. 2018;8(1):4768.

27. Lowry OH, Rosebrough NJ, Farr AL, Randall RJ. Protein measurement with the Folin phenol reagent. Journal of biological chemistry. 1951;193(1):265-75.

28. Frässdorf J, Borowski A, Ebel D, Feindt P, Hermes M, Meemann T, et al. Impact of preconditioning protocol on anesthetic-induced cardioprotection in patients having coronary artery bypass surgery. The Journal of thoracic and cardiovascular surgery. 2009;137(6):1436-42, 42.e1.

29. Boden H, Ahmed TA, Velders MA, van der Hoeven BL, Hoogslag GE, Bootsma M, et al. Peak and fixedtime high-sensitive troponin for prediction of infarct size, impaired left ventricular function, and adverse outcomes in patients with first ST-segment elevation myocardial infarction receiving percutaneous coronary intervention. Am J Cardiol. 2013;111(10):1387-93.

30. Ferdinandy P, Hausenloy DJ, Heusch G, Baxter GF, Schulz R. Interaction of Risk Factors, Comorbidities, and Comedications with Ischemia/Reperfusion Injury and Cardioprotection by Preconditioning, Postconditioning, and Remote Conditioning. Pharmacological Reviews. 2014;66(4):1142-74. 
31. Kleinbongard P, Neuhauser M, Thielmann M, Kottenberg E, Peters J, Jakob H, et al. Confounders of Cardioprotection by Remote Ischemic Preconditioning in Patients Undergoing Coronary Artery Bypass Grafting. Cardiology. 2016;133(2):128-33.

32. Zhou C, Liu Y, Yao Y, Zhou S, Fang N, Wang W, et al. $\beta$-blockers and volatile anesthetics may attenuate cardioprotection by remote preconditioning in adult cardiac surgery: a meta-analysis of 15 randomized trials. Journal of cardiothoracic and vascular anesthesia. 2013;27(2):305-11.

33. Landoni G, Biondi-Zoccai GGL, Zangrillo A, Bignami E, D'Avolio S, Marchetti C, et al. Desflurane and sevoflurane in cardiac surgery: a meta-analysis of randomized clinical trials. Journal of cardiothoracic and vascular anesthesia. 2007;21(4):502-11.

34. Julier K, da Silva R, Garcia C, Bestmann L, Frascarolo P, Zollinger A, et al. Preconditioning by sevoflurane decreases biochemical markers for myocardial and renal dysfunction in coronary artery bypass graft surgery: a double-blinded, placebo-controlled, multicenter study. Anesthesiology. 2003;98(6):1315-27.

35. Zangrillo A, Musu M, Greco T, Di Prima AL, Matteazzi A, Testa V, et al. Additive Effect on Survival of Anaesthetic Cardiac Protection and Remote Ischemic Preconditioning in Cardiac Surgery: A Bayesian Network Meta-Analysis of Randomized Trials. PLoS One. 2015;10(7):e0134264.

36. Kottenberg E, Thielmann M, Bergmann L, Heine T, Jakob H, Heusch G, et al. Protection by remote ischemic preconditioning during coronary artery bypass graft surgery with isoflurane but not propofol - a clinical trial. Acta anaesthesiologica Scandinavica. 2012;56(1):30-8.

37. Kottenberg E, Musiolik J, Thielmann M, Jakob H, Peters J, Heusch G. Interference of propofol with signal transducer and activator of transcription 5 activation and cardioprotection by remote ischemic preconditioning during coronary artery bypass grafting. The Journal of thoracic and cardiovascular surgery. 2014;147(1):376-82.

38. Nederlof R, Weber NC, Juffermans NP, de Mol BA, Hollmann MW, Preckel B, et al. A randomized trial of remote ischemic preconditioning and control treatment for cardioprotection in sevoflurane-anesthetized CABG patients. BMC anesthesiology. 2017;17(1):51.

39. Wu Q, Wang T, Chen S, Zhou Q, Li H, Hu N, et al. Cardiac protective effects of remote ischaemic preconditioning in children undergoing tetralogy of fallot repair surgery: a randomized controlled trial. European Heart Journal. 2017:ehx030.

40. Kottenberg E, Musiolik J, Thielmann M, Jakob H, Peters J, Heusch G. Interference of propofol with signal transducer and activator of transcription 5 activation and cardioprotection by remote ischemic preconditioning during coronary artery bypass grafting. J Thorac Cardiovasc Surg. 2014;147(1):376-82. 
41. Xu X, Zhou Y, Luo S, Zhang W, Zhao Y, Yu M, et al. Effect of remote ischemic preconditioning in the elderly patients with coronary artery disease with diabetes mellitus undergoing elective drug-eluting stent implantation. Angiology. 2014;65(8):660-6.

42. Wang B, Raedschelders K, Shravah J, Hui Y, Safaei HG, Chen DD, et al. Differences in myocardial PTEN expression and Akt signalling in type 2 diabetic and nondiabetic patients undergoing coronary bypass surgery. Clin Endocrinol (Oxf). 2011;74(6):705-13.

43. Anderson EJ, Rodriguez E, Anderson CA, Thayne K, Chitwood WR, Kypson AP. Increased propensity for cell death in diabetic human heart is mediated by mitochondrial-dependent pathways. Am J Physiol Heart Circ Physiol. 2011;300(1):H118-24.

\section{Table 1}

Table 1. Baseline characteristics and demographics 
$\begin{array}{lll}\text { Patients } & \text { p- } & \text { Patients } \\ \text { without } & \text { value } & \text { with } \\ \text { diabetes (24) } & & \text { diabetes } \\ & & (26)\end{array}$

Control (11) Intervention

(13)

\begin{tabular}{|c|c|c|c|c|c|c|}
\hline Age (meanıSD) & $67 \pm 8$ & $66 \pm 6$ & 0.59 & $63 \pm 7$ & $69 \pm 11$ & 0.65 \\
\hline Male sex n(\%) & $12(92)$ & $10(91)$ & 1 & $9(69)$ & $11(85)$ & 0.65 \\
\hline Body mass index & $26 \pm 3$ & $28 \pm 4$ & 0.20 & $30 \pm 4$ & $30 \pm 5$ & 0.20 \\
\hline Euroscore & $3.5 \pm 2$ & $2.8 \pm 2$ & 0.35 & $2.5 \pm 1$ & $3.2 \pm 2$ & 0.35 \\
\hline NYHA class angina & & & 0.58 & & & 0.42 \\
\hline 1 & 0 & 0 & & $1(8)$ & $0(0)$ & \\
\hline 2 & $4(31)$ & $6(55)$ & & $6(46)$ & $2(17)$ & \\
\hline 3 & $6(46)$ & $4(36)$ & & $3(23)$ & $6(50)$ & \\
\hline 4 & $1(8)$ & $10(42)$ & & $2(15)$ & $2(17)$ & \\
\hline $\begin{array}{l}\text { Prior myocardial } \\
\text { infarction }\end{array}$ & $3(23)$ & $1(9)$ & 0.60 & $6(46)$ & $5(39)$ & 1 \\
\hline $\begin{array}{l}\text { Ejection Fraction } \\
>50\end{array}$ & 1 & & & $10(77)$ & & \\
\hline $\begin{array}{l}\text { Ejection Fraction 30- } \\
50\end{array}$ & & & & $2(15)$ & & \\
\hline Left main stenosis & $8(62)$ & $3(27)$ & 0.12 & $7(54)$ & $3(23)$ & 0.23 \\
\hline $\begin{array}{l}\text { Percutaneous } \\
\text { coronary } \\
\text { intervention }\end{array}$ & 0 & & & $0(0)$ & $1(8)$ & 0.045 \\
\hline Smoker & $9(69)$ & $5(46)$ & 0.41 & $10(77)$ & $3(23)$ & 0.017 \\
\hline Hypertension & $6(46)$ & $6(54)$ & 1 & $9(69)$ & $11(85)$ & 0.65 \\
\hline Dyslipidemia & $4(31)$ & $5(46)$ & 0.68 & $6(46)$ & $9(69)$ & 0.43 \\
\hline Family history & $6(46)$ & $3(27)$ & 0.42 & $5(39)$ & $5(39)$ & 1 \\
\hline $\begin{array}{l}\text { NYHA class } \\
\text { heartfailure }\end{array}$ & & & 0.10 & & & 0.53 \\
\hline 1 & $7(54)$ & $7(64)$ & & $8(62)$ & $10(77)$ & \\
\hline 2 & $2(15)$ & $4(36)$ & & $2(15)$ & $2(15)$ & \\
\hline 3 & $4(31)$ & 0 & & $2(15)$ & $2(15)$ & \\
\hline
\end{tabular}

Control Intervention

(13) (13)

pvalue

value 


\begin{tabular}{|c|c|c|c|c|c|c|}
\hline 4 & 0 & 0 & & 0 & 0 & \\
\hline \multicolumn{7}{|l|}{ Medication } \\
\hline Statin & $12(92)$ & $11(100)$ & 1 & $13(100)$ & $12(92)$ & 1 \\
\hline Beta blocker & $8(62)$ & $10(91)$ & 0.17 & $11(85)$ & $12(93)$ & 1 \\
\hline $\begin{array}{l}\text { Angiotensin } \\
\text { converting enzyme } \\
\text { inhibiters }\end{array}$ & $4(31)$ & $1(9)$ & 0.33 & $7(54)$ & $3(23)$ & 0.23 \\
\hline $\begin{array}{l}\text { Angiotensin receptor } \\
\text { blocker }\end{array}$ & $3(23)$ & $4(36)$ & 0.66 & $2(15)$ & $5(39)$ & 0.38 \\
\hline Calcium & $3(23)$ & $3(27)$ & 1 & $4(31)$ & $6(46)$ & 0.67 \\
\hline Diuretics & $1(8)$ & $3(27)$ & 0.30 & $5(39)$ & $5(39)$ & 1 \\
\hline Nitrates & $5(39)$ & $3(27)$ & 0.68 & $3(23)$ & $6(46)$ & 0.41 \\
\hline Aspirin & $11(85)$ & $10(91)$ & 1 & $11(85)$ & $10(77)$ & 1 \\
\hline Clopidogrel & $4(31)$ & $3(27)$ & 1 & $6(46)$ & $5(39)$ & 1 \\
\hline $\begin{array}{l}\text { Dual anti platelet } \\
\text { therapy }\end{array}$ & $4(31)$ & $3(27)$ & 1 & $5(39)$ & $5(39)$ & 1 \\
\hline Insulin & 0 & 0 & & 5 (39) & 5 (39) & 1 \\
\hline Biguanide & 0 & 0 & & $12(92)$ & $9(69)$ & 0.32 \\
\hline Sulfonylurea & 0 & 0 & & $3(23)$ & $3(23)$ & 1 \\
\hline
\end{tabular}

\section{Figures}


p/t ERK1

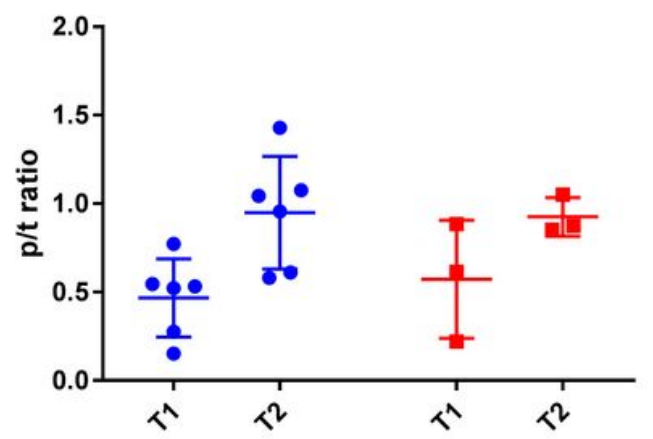

p/t STAT3

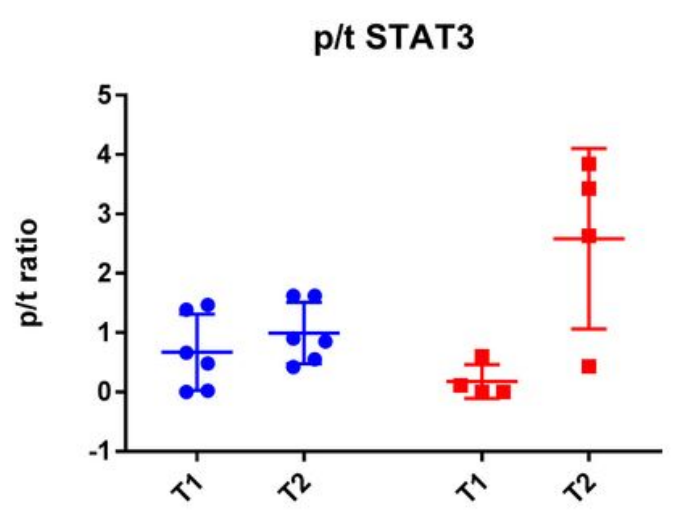

- Control

- RIPC

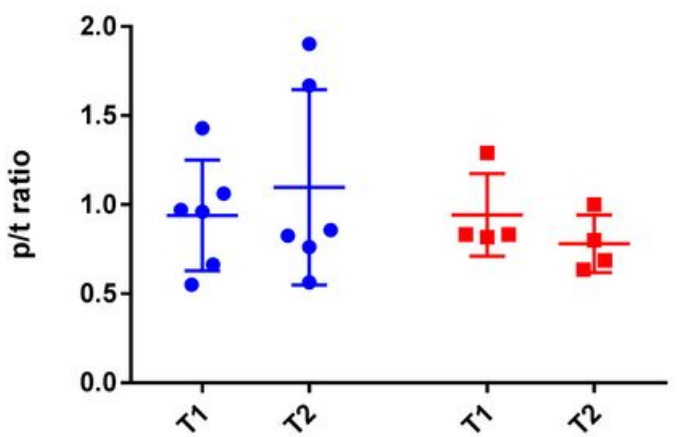

- Control

- RIPC

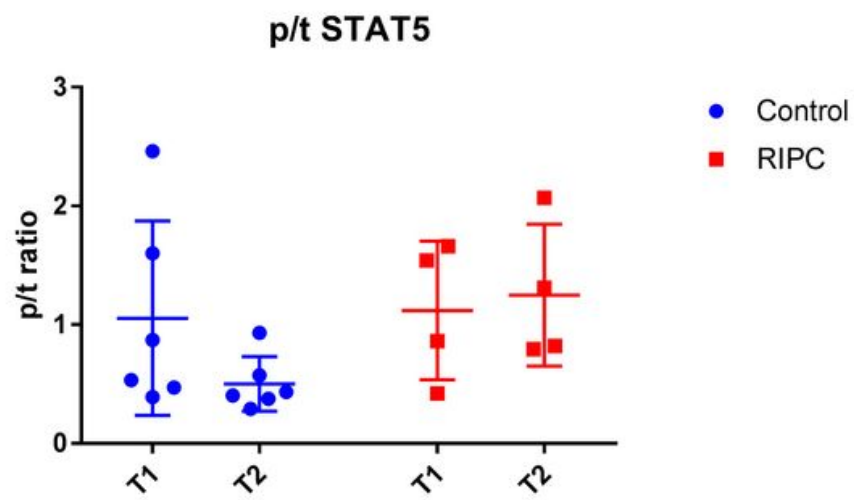

- Control

- RIPC

Figure 1

p/t ratio of ERK1, ERK2, STAT3 and STAT5 in patients without diabetes 

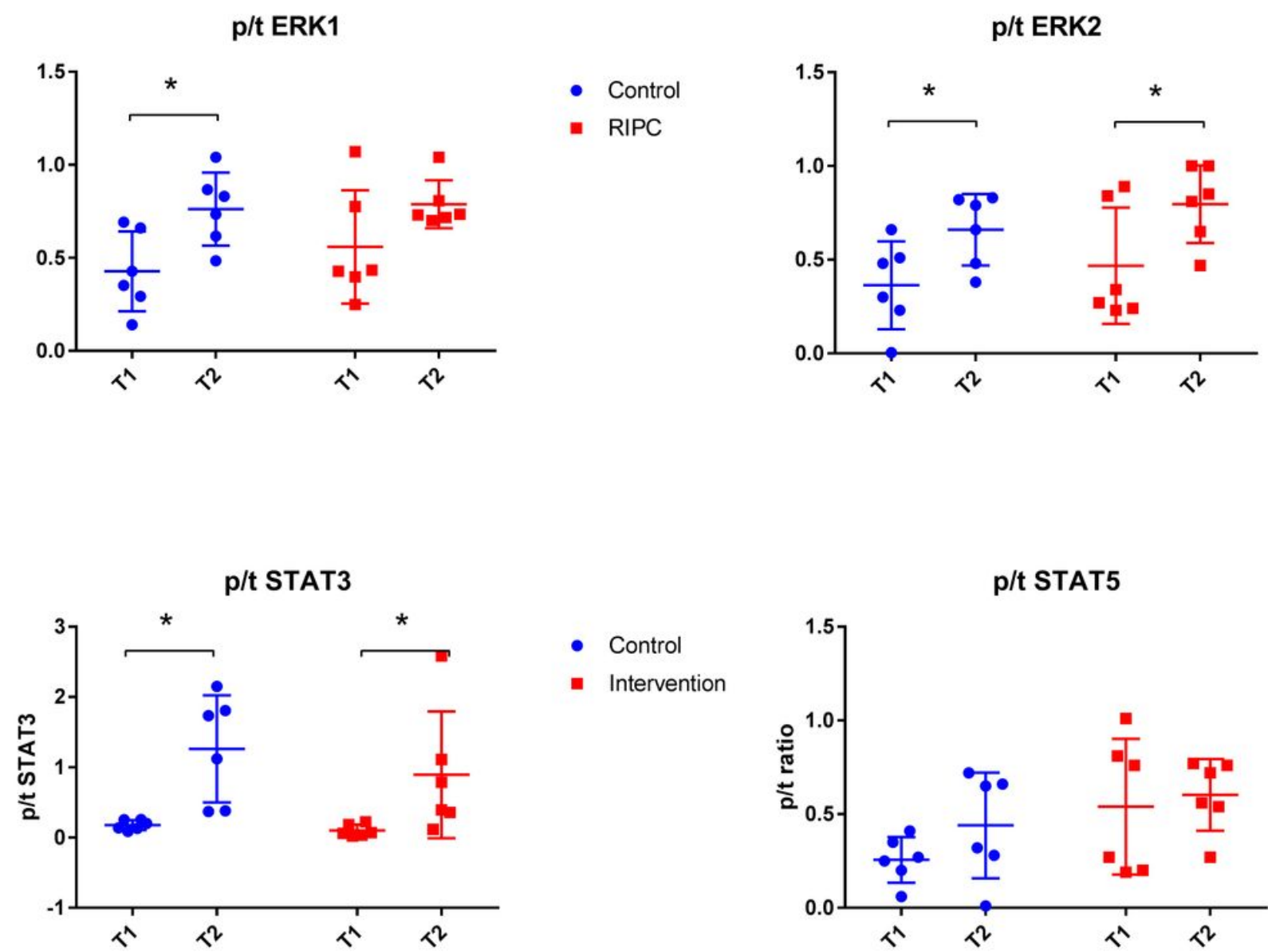

- Control

- RIPC

- Control

- RIPC

- Control

- Intervention

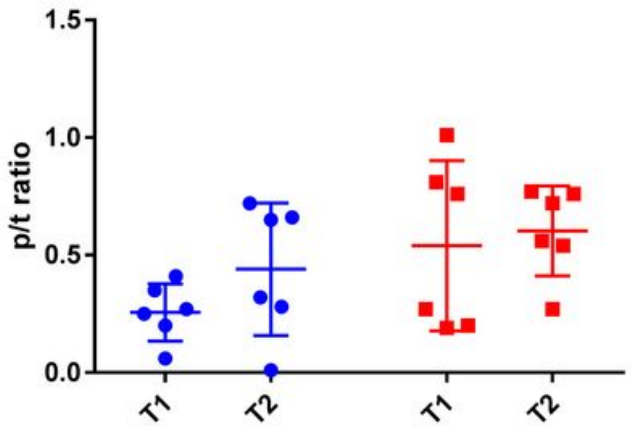

- Control

- RIPC

Figure 2

$\mathrm{p} / \mathrm{t}$ ratio of ERK1, ERK2, STAT3 and STAT5 in patients with diabetes 
p/t ERK1
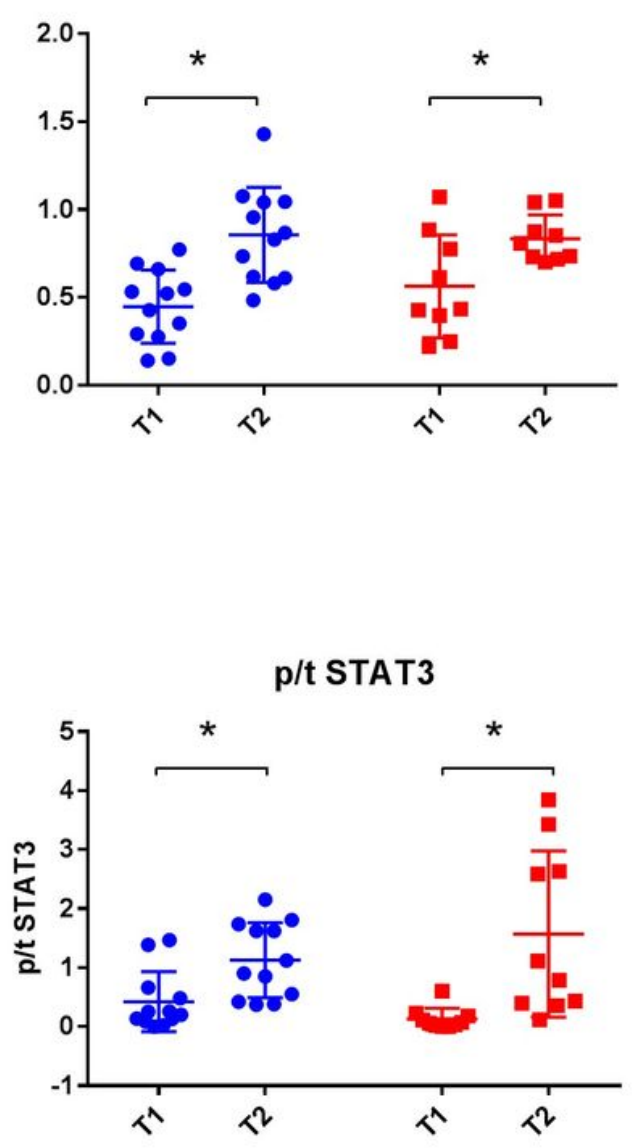

- Control

- RIPC p/t ERK2

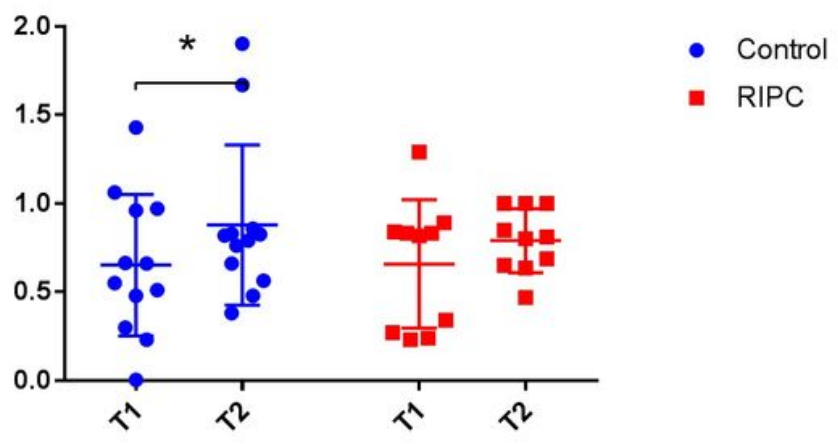

p/t STAT5

- Control

- Intervention

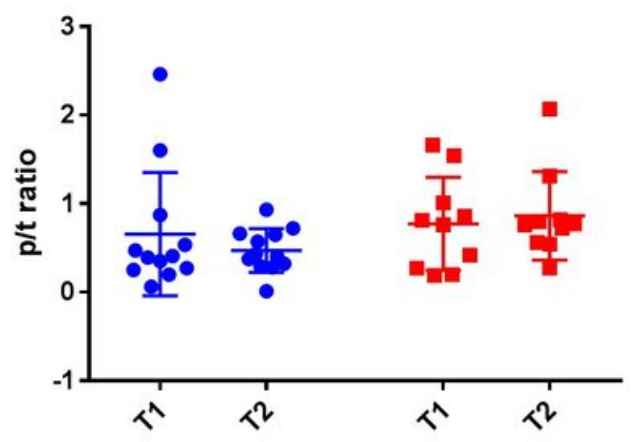

Figure 3

p/t ratio of ERK1, ERK2, STAT3 and STAT5 in all patients combined 


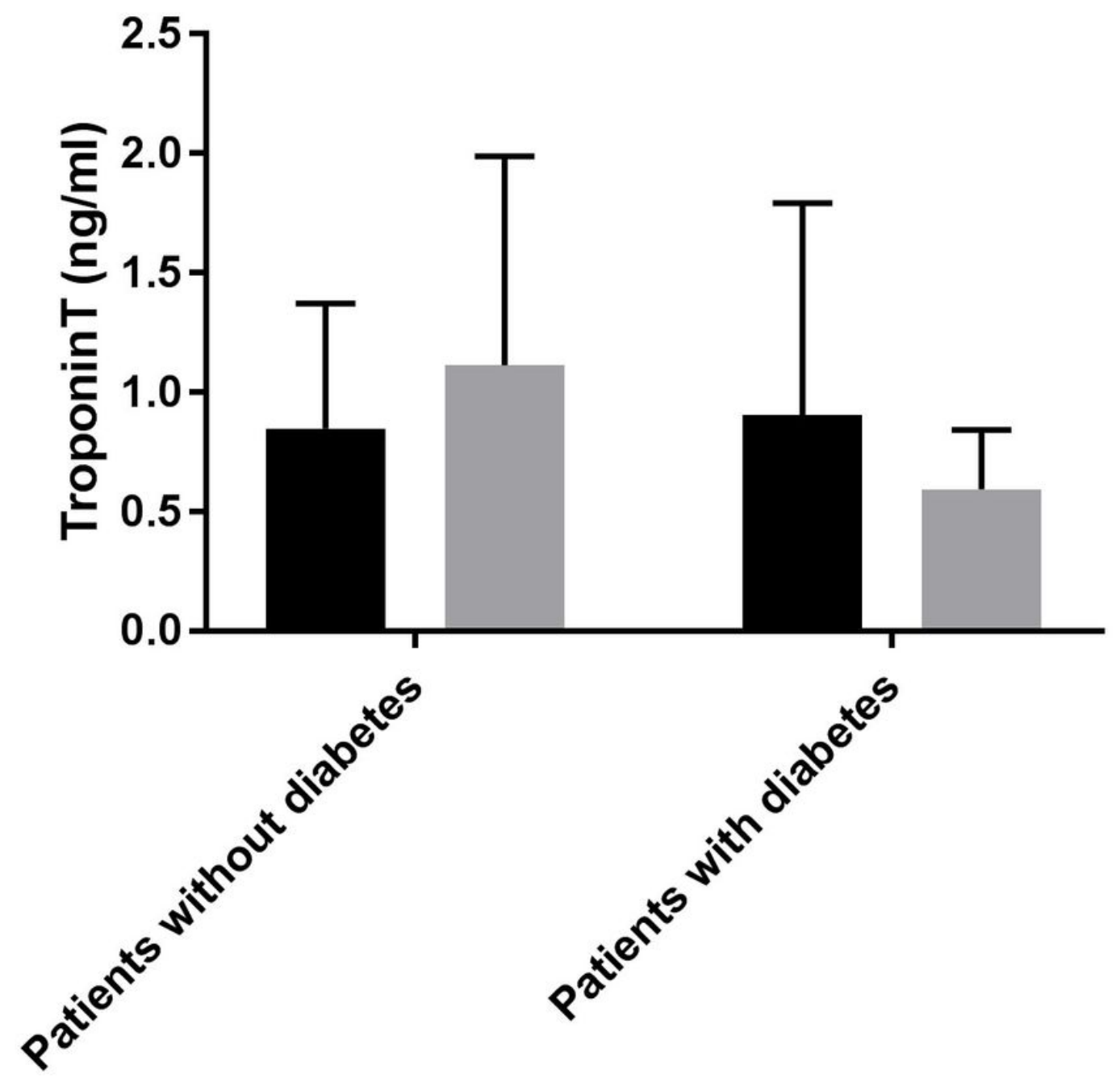

Figure 4

Peak troponin T levels ( $\mathrm{ng} / \mathrm{mmol}$ ) in control (black) versus RIPC (grey) treated patients, in patients with and without diabetes 


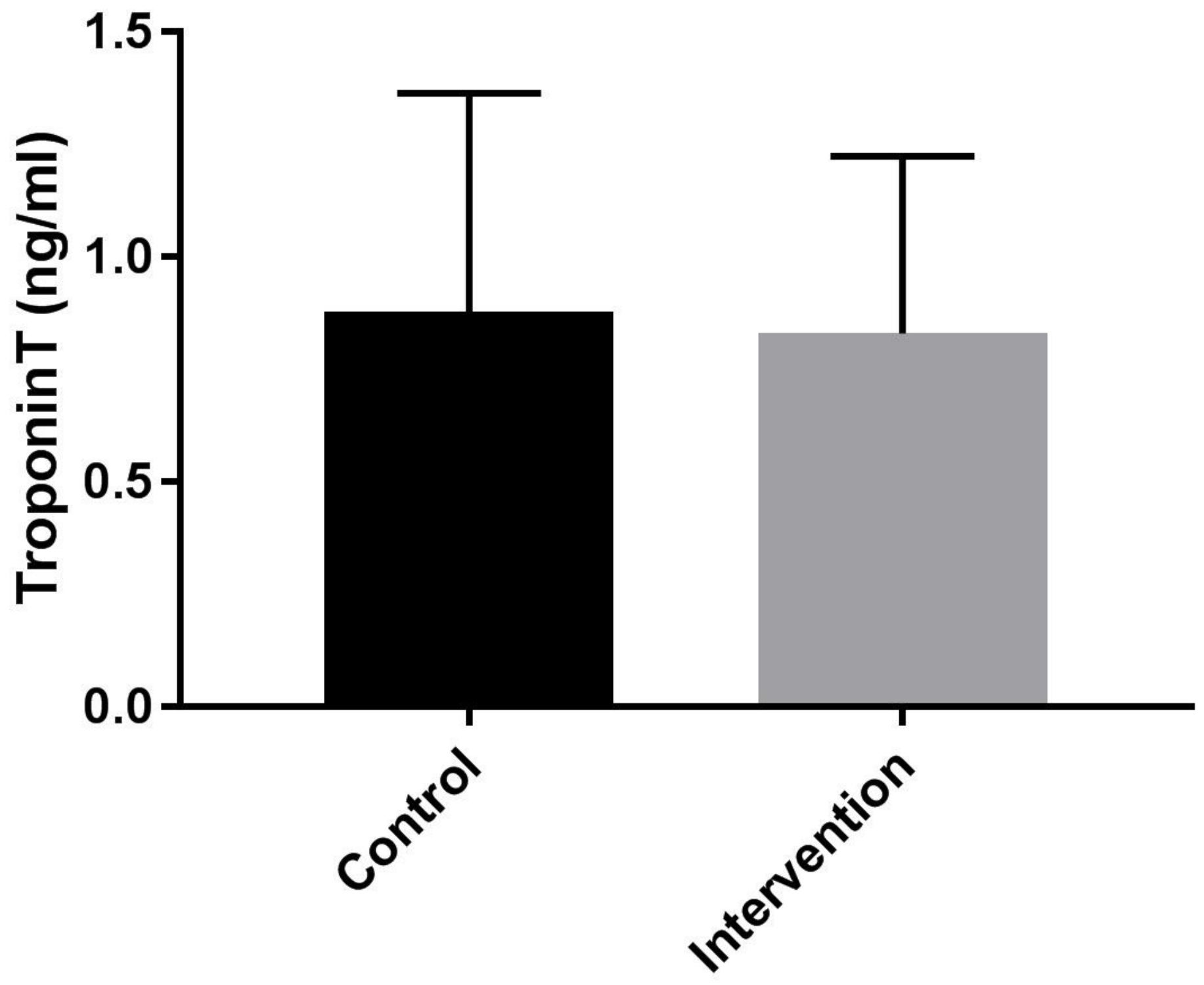

Figure 5

Peak troponin T levels $(\mathrm{ng} / \mathrm{mmol}$ ) in control (black) versus RIPC (grey) treated patients, in all patients combined

\section{Supplementary Files}

This is a list of supplementary files associated with this preprint. Click to download.

- CONSORT2010Checklist.doc 